\title{
Effects of the DASH-JUMP dietary intervention in Japanese participants with high-normal blood pressure and stage 1 hypertension: an open-label single-arm trial
}

\author{
Atsuko Kawamura ${ }^{1,2}$, Katsuko Kajiya ${ }^{1}$, Hiroko Kishi ${ }^{1}$, Junko Inagaki ${ }^{2}$, Makoto Mitarai ${ }^{3}$, Hiroshi Oda ${ }^{3}$, \\ Seiji Umemoto ${ }^{4}$ and Sei Kobayashi ${ }^{1}$
}

The Dietary Approaches to Stop Hypertension (DASH) diet is recommended by the American Heart Association to lower blood pressure (BP); however, its effects in Japanese participants have not been rigorously studied. We assessed the effects of the DASH-Japan Ube Modified diet Program (DASH-JUMP), a modified DASH diet, on cardiometabolic and inflammatory biomarkers in Japanese participants with untreated high-normal BP or stage 1 hypertension. Fifty-eight participants (30 men and 28 women; mean age $54.1 \pm 8.1$ years) with untreated high-normal BP or stage 1 hypertension followed the DASH-JUMP (salt $8.0 \mathrm{~g}$ per day) for 2 months. After the intervention period, they resumed their usual diets for 4 months. The DASH-JUMP significantly decreased the participants' body mass index values $\left(24.6 \pm 3.5 \mathrm{~kg} \mathrm{~m}^{-2}\right.$ at baseline $\rightarrow 23.2 \pm 3.3 \mathrm{~kg} \mathrm{~m}^{-2}$ at 2 months, $P=0.000)$, BP $(153 \pm 14 / 91 \pm 11 \mathrm{~mm} \mathrm{Hg}$ at baseline $\rightarrow 130 \pm 16 / 80 \pm 9 \mathrm{~mm} \mathrm{Hg}$ at 2 months, $P=0.000$ and $139 \pm 16 / 85 \pm 10 \mathrm{~mm} \mathrm{Hg}$ at 6 months, $P=0.000)$, fasting serum glucose level $\left(100 \pm 26 \mathrm{mg} \mathrm{dl}^{-1} \rightarrow 94 \pm 15 \mathrm{mg} \mathrm{dl}^{-1}\right.$ at 2 months, $P=0.003)$ and fasting insulin level $\left(6.9 \pm 5.9 \mu \mathrm{IU} \mathrm{ml}^{-1} \rightarrow 4.4 \pm 2.7 \mu \mathrm{lU} \mathrm{ml} \mathrm{m}^{-1}\right.$ at 2 months, $\left.P=0.000\right)$. The mean compliance of the participants for the DASH-JUMP diet was $88.5 \%$. The DASH-JUMP diet reduced cardiovascular risk factors and may be an effective nutritional strategy for preventing cardiovascular events.

Hypertension Research (2016) 39, 777-785; doi:10.1038/hr.2016.76; published online 14 July 2016

Keywords: blood pressure; Dietary Approaches to Stop Hypertension diet; Japanese; lifestyle-related disease

\section{INTRODUCTION}

Between 1990 and 2010, the number of people aged 65 years and older in Japan almost doubled from 15 million to 29 million. In 2010, this older demographic represented $23 \%$ of the Japanese population, which was the highest proportion among any population worldwide. ${ }^{1}$ The second 'Healthy Japan 21' policy released by the Ministry of Health, Labor and Welfare declares the aims of 'decreasing the health status disparity' and 'increasing the healthy life expectancy'. To achieve these goals, it is important to prevent the onset and the subsequent aggravation of lifestyle-related diseases. High blood pressure (BP) is a major risk factor for cardiovascular and cerebrovascular diseases. ${ }^{3-5}$ Almost 43 million Japanese adults, which constitute $\sim 35 \%$ of the adult Japanese population, have hypertension. ${ }^{6}$ In terms of national medical expenditure, hypertension has the second greatest economic burden on Japanese society among all diseases. ${ }^{2}$
The main treatments prescribed for hypertension are medication, dietary interventions and exercise. ${ }^{4,7-9}$ Many patients with hypertension prefer to undergo lifestyle-based treatments without using drugs. The main dietary treatment approach implemented in Japan is the reduction of daily dietary sodium intake. ${ }^{10-15}$

Dietary Approaches to Stop Hypertension (DASH) is one of the most widely used dietary interventions for hypertension in countries outside Japan and is recommended by the American Heart Association. Preliminary research results ${ }^{16-18}$ have shown that the DASH diet lowers BP in those who normally have high, intermediate and low sodium intake levels and has been recommended for the prevention and treatment of hypertension. When augmented by exercise and weight loss, the DASH diet can offer considerable benefit to patients with high $\mathrm{BP}$, not only through reduction of BP but also through the favorable modification of other biomarkers of disease risk. ${ }^{19,20}$

${ }^{1}$ Department of Molecular Physiology and Medical Bioregulation, Yamaguchi University Graduate School of Medicine, Ube, Japan; ${ }^{2}$ Faculty of Health Sciences, Yamaguchi University Graduate School of Medicine, Ube, Japan; ${ }^{3}$ Central Research Institute, Maruha Nichiro Corporation, Tsukuba, Japan and ${ }^{4}$ Center for Clinical Research, Yamaguchi University Hospital, Ube, Japan

Correspondence: Associate Professor A Kawamura, Department of Molecular Physiology and Medical Bioregulation, Yamaguchi University Graduate School of Medicine, 1-1-1Minami-Kogushi, Ube, Yamaguchi 755-8505, Japan.

E-mail: atsuko@yamaguchi-u.ac.jp

Received 19 November 2015; revised 12 April 2016; accepted 24 April 2016; published online 14 July 2016 
The Japanese Guidelines for the Management of Hypertension 2009 (JSH) recommend the DASH diet for people with hypertension. However, few people are aware of the DASH diet in Japan, and the effect of the DASH diet in Japanese participants with hypertension has not been previously investigated. Japanese cuisine or 'Washoku' was registered by United Nations Educational, Scientific and Cultural Organization (UNESCO) as an intangible cultural heritage of humanity in December 2013. ${ }^{21}$ Traditional food cultures such as Washoku are strong influences on the diet of Japanese people. However, as the DASH diet was designed for European and American populations, it is difficult for Japanese people to follow the original DASH diet because of the large differences in dietary patterns and taste preferences between the people in Japan and those in western countries. It is also believed that popularizing the DASH diet in Japan is difficult because it is difficult to design a menu that matches the nutrient composition of the DASH diet using local Japanese ingredients.

Our research group collaborated with nurses, physicians, dietitians and experts in commercial food development. Through our collaborations, we developed a modified DASH diet for the use of Japanese people, and, with the aim of making the DASH diet widely available in Japan, we determined the effects of a modified DASH diet, the DASH-Japan Ube Modified Diet Program (DASH-JUMP), in an open-label, single-arm trial.

\section{METHODS}

\section{DASH-JUMP}

The original DASH diet menu items were cornflakes, salad, marinades, milk and fruit juices, ${ }^{22}$ which were difficult for Japanese people to consume on a regular basis. Therefore, we developed a modified DASH diet that we called DASH-JUMP. DASH-JUMP is tailored for the Japanese food culture with the same nutrient composition as that of the original DASH diet, ${ }^{23}$ and is generally better accepted by Japanese people. Whole grain brown rice was adopted as the staple food, because it matched Japan's food culture, which is based on rice. We were careful to include a meal with soup once a day, because Japanese people typically consume meals involving a bowl of soup and one side dish daily in their ordinary diet. Furthermore, we included many local dishes of Yamaguchi Prefecture and used a wide range of dishes from the repertoire of typical Japanese food.

The DASH-JUMP involved a 14-day menu cycle with 42 meals at 2 calorie levels ( 1650 and $1820 \mathrm{kcal}$ per day). DASH-JUMP menu items were low in calories but offered sufficient satiety because of their chewy texture.

DASH-JUMP menu was created in accordance with the nutritional composition of the original DASH diet. However, as a result of measuring the nutritional composition of menu items after cooking, DASH-JUMP contained less total fat and saturated fatty acids than the original DASH diet. In addition, it contained more protein and carbohydrates than the original DASH diet. DASH-JUMP is rich in fruits, vegetables and low-fat dairy foods. DASH-JUMP provides almost double the quantity of potassium, calcium, magnesium and fiber of that consumed in the average Japanese diet. ${ }^{24}$ The salt content of DASH-JUMP is $\sim 8.0 \mathrm{~g}$ per day. A total of 1820 and $1650 \mathrm{kcal}$ contain the same amount of salt. Both were same nutrient composition, but excluding protein and carbohydrates. Table 1 shows the nutrient compositions of the original DASH diet, DASH-JUMP and the average Japanese intake. After menus were cooked, we evaluated the nutrient composition of DASH-JUMP by chemical analysis of the food items in the menus at the Central Research Institute of Maruha Nichiro Corporation, Tokyo, Japan. In addition, we showed a sample of the menus and images of the menu items for one day of DASH-JUMP.

\section{Ethical considerations}

The study was conducted in accordance with the Declaration of Helsinki and the Ethical Guidelines for Clinical Studies in Japan. It was approved by the Ethics Committee of Yamaguchi University Faculty of Medicine and Health
Sciences. Written informed consent was obtained from the participants who agreed to participate in the study.

\section{Study participants}

We recruited study participants between November 2011 and January 2012 through advertisements at companies and hospitals in the cities of Ube, Yamaguchi and Shimonoseki in the Yamaguchi prefecture of Japan, and in a local newspaper. This study included 60 participants (31 men and 29 women) aged 36-69 years who were not taking antihypertensive medication. They had a mean systolic BP (SBP) between 130 and $159 \mathrm{~mm} \mathrm{Hg}$, or a mean diastolic BP (DBP) between 85 and $99 \mathrm{~mm} \mathrm{Hg}$, or both. Participants' BP values were monitored with an automatic sphygmomanometer for 5 days before the commencement of the study.

\section{Criteria for eligibility}

To be eligible, participants had to be in the age range of 20-70 years. Both men and women were recruited. Participants or members of their families performed their sphygmomanometry measurements two times per day at home. For eligibility, the results of these measurements taken during the 5 days before the study had to show values within the high-normal range of BP (130-139 mm Hg/85-89 mm Hg) or stage 1 hypertension (140-159 mm Hg/ 90-99 mm Hg).

The major exclusion criteria were previously diagnosed kidney disease, blood urea nitrogen $>22 \mathrm{mg} \mathrm{dl}^{-1}$, creatinine $>1.3 \mathrm{mg} \mathrm{dl}^{-1}$ for men and $>0.9 \mathrm{mg} \mathrm{dl}^{-1}$ for women, renal dysfunction, a previous cardiovascular event, organ derangement, diabetes mellitus requiring insulin or oral hypoglycemic treatments, dementia, food allergy and unwillingness to stop taking vitamin and mineral supplements. We also excluded women who were pregnant and receiving postmenopausal hormonal therapy.

\section{Intervention}

Participants were treated with DASH-JUMP (salt $8.0 \mathrm{~g}$ per day) for 2 months, and for the period of 4 months following the cessation of the intervention, they consumed their usual diets. It was reported that the DASH diet lowered BP in 2 weeks, ${ }^{22}$ but because this was the first study of a modified DASH diet in a Japanese population, we planned to perform two rounds using a 14-day menu and decided to observe the effect of the diet on the physical symptoms of the participants. Also, the reason that the intervention period was planned to last for 2 months was to ascertain whether the menu contents were sufficiently acceptable for Japanese participants to continue complying with DASH-JUMP for the period of 2 months.

Participants' BP values were monitored daily with an automatic BP monitor in their home for the total period of 6 months. We took BP measurements in our laboratory before starting the DASH-JUMP, 1 and 2 months after the commencement of the program and 4 months after the cessation DASH-JUMP intervention.

All food was prepared in a single food center according to a standardized protocol, and three meals of the DASH-JUMP diet were delivered to the workplaces of the study participants or their homes every day. During the study period, participants were directed not to change any of their conventional habits other than their diet.

\section{Outcome measurements}

SBP and DBP measurements made during the medical examinations in our laboratory for the duration of the study period were the primary outcome measures. Participants' body weight, body mass index (BMI) values, abdominal circumference, hip circumference, BP measurements made at home, fasting serum glucose levels, fasting insulin levels, serum and urinary potassium and sodium levels, urinary microalbumin levels, homeostatic model assessments of insulin resistance (HOMA-IR) and homeostatic model assessment $\beta$-cell function (HOMA- $\beta$ ), and serum levels of total cholesterol, low-density lipoprotein-cholesterol (LDL-C), high-density lipoprotein-cholesterol (HDLC), triglycerides, apolipoproteins (apo) A-1, B and E, homocysteine, uric acid, adiponectin, aspartate aminotransferase (AST), alanine aminotransferase (ALT), $\gamma$-glutamyl transpeptidase $(\gamma$-GTP), renin, hemoglobin AlC (HbAlC), interleukin-6 (IL-6), N-terminal prohormone of brain natriuretic peptide 


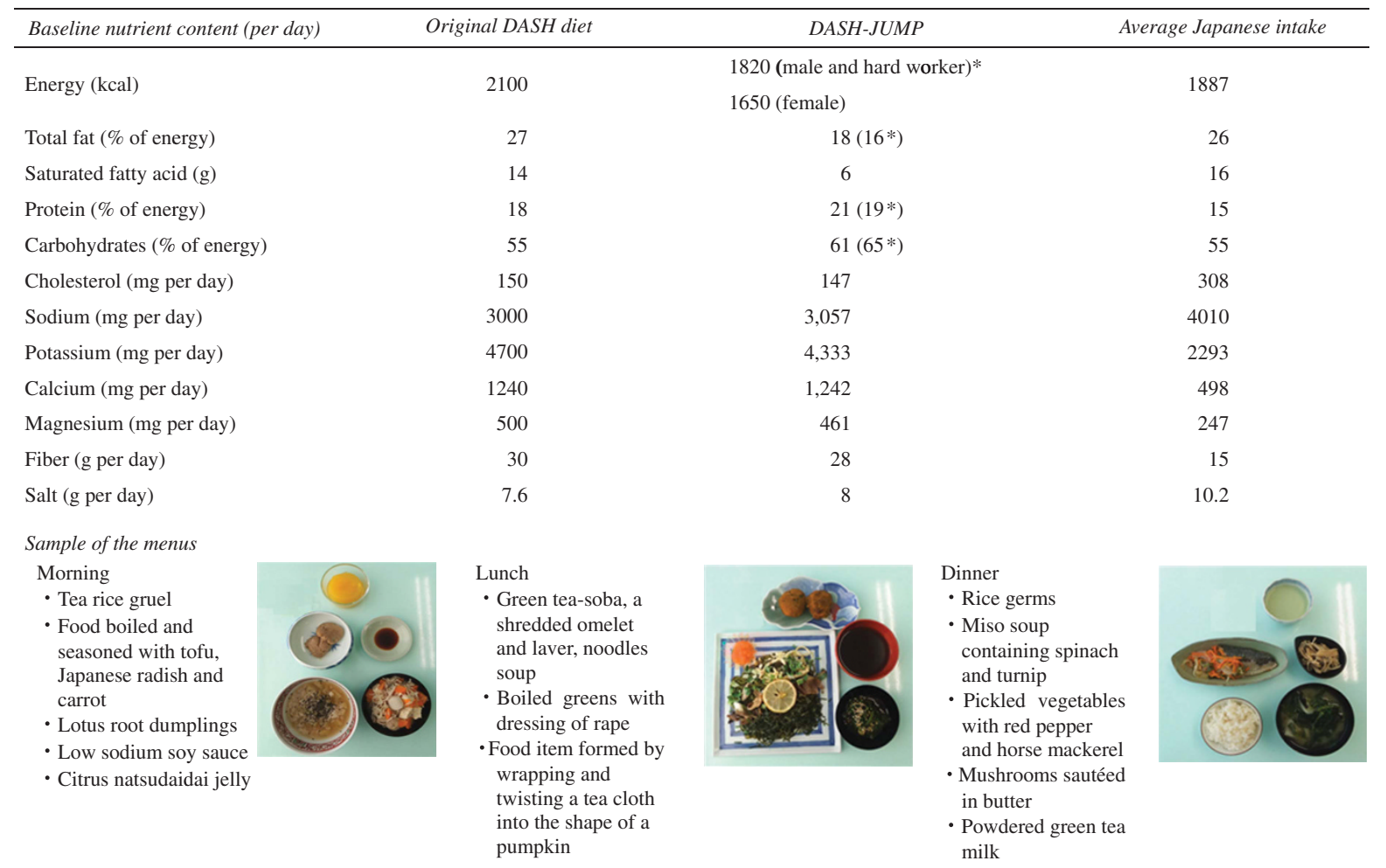

Abbreviations: DASH, Dietary Approaches to Stop Hypertension; DASH-JUMP, DASH-Japan Ube Modified diet Program.

Data of nutrient composition are means, $n=42$ menus. As for the energy content of DASH-JUMP of 1820 kcal per day, the diet had a baseline nutrient constitution of 1650 kcal per day and we regulated it by increasing the quantity of rice by $60 \mathrm{~g}$ for breakfast and supper.

*The nutrient content that changed in the case of $1820 \mathrm{kcal}$.

(NT-proBNP) and high sensitivity C-reactive protein (hs-CRP) were secondary outcome measures. Furthermore, we add apoB/apoA-1 ratio that is an effective predictor of coronary heart disease risk as secondary outcome measures.

\section{Anthropometric parameters and BP measurements}

After abdominal circumference measurements at the level of the umbilicus, body weight and BMI were measured with a body composition analyzer (DF860K; Yamato Scale, Akashi, Hyogo, Japan) using the bioelectrical impedance analysis method. Abdominal circumference was measured in unclothed participants. Body weight and BMI were measured in the morning; the participants wore examination clothes but not shoes at this time. BMI was calculated as $\mathrm{kg} \mathrm{m}^{-2}$. Participants measured their BP at home from the upper arm using an oscillometric device (HEM-7080 IC; Omuron, Kyoto, Japan) in compliance with the Japanese Society of Hypertension Guidelines for Selfmonitoring of Blood Pressure at Home (Second Edition). The BP measurements were taken in the morning within $1 \mathrm{~h}$ waking up, after urination and before breakfast after a 1-2 min rest in a sitting position, and in the evening after a 1-2 min rest in the sitting position. ${ }^{25}$ When participants visited our laboratory, BP was measured according to the JSH (2009). At the laboratory, BP was measured using an HEM-7080 IC sphygmomanometer (Omuron) after participants had rested for a few minutes in the seated position on a chair with a back support and with their legs uncrossed. Participants' body weight, BMI values, abdominal circumference, hip circumference and $\mathrm{BP}$ were analyzed at baseline and at the follow-up visits after 1, 2, 3 and 6 months.

\section{Laboratory measurements}

All the blood and urine samples were collected at our laboratory from fasting participants and were measured by a central laboratory (SRL, Tokyo, Japan).
Serum cholesterol and triglycerides levels were measured by an enzymatic method, HDL-C levels by direct measurement and hs-CRP levels by the nephelometry method. After participants had rested by lying in bed for $30 \mathrm{~min}$, blood was drawn for renin and NT-proBNP measurements. The blood and urine samples were analyzed at baseline and at the follow-up visits after 1,2, and 6 months.

\section{Assessment of food intake}

They kept a daily record of their intake of food on the DASH-JUMP menu and food outside this menu. We prepared a life checklist that displayed a photograph of each menu item so that participants could precisely record their intake of each meal, with 10 phases of evaluation every day. They also recorded a self-assessment of their physical condition every day using a checklist questionnaire.

\section{Statistical analyses}

Analyses were performed using SPSS version 21.0 for Windows (IBM, Armonk, NY, USA). Variables with a skewed distribution were logarithmically transformed for statistical analyses. The effects of indices of lifestyle-related diseases, serum lipids, insulin sensitivity, inflammatory cytokines and others and electrolyte concentrations in serum and urine were compared by repeatedmeasures analysis of variance or Friedman's test as appropriate. Further, we compared at each time-point with post hoc analysis by Bonferroni or Friedman's test for multiple comparisons. We showed the significant differences from baseline to each point on the table. And about the characteristic change, we indicated it in results. Multiple regression analysis was used to determine independent predictors of cardiometabolic and inflammatory biomarkers. 
We use the changes in SBP from baseline to 1 month or 2 months and the change in DBP from baseline to 1 month or 2 months as a dependent variable. We used the changes of cardiometabolic and inflammatory biomarkers from baseline to 1 month or 2 months of the DASH-JUMP diet as independent variables.

\section{RESULTS}

\section{Participant enrolment}

One hundred and thirteen adults were screened for the study and 60 Japanese participants were enrolled. Of these participants, one met our initial exclusion criteria and was excluded at baseline. Another had an infection and retired from the study 1 month after starting. The infection that the participant had did not have the association with DASH-JUMP. Figure 1 shows a flow diagram of the phases of the DASH-JUMP study. In total, 58 participants completed the study and were analyzed. The mean age of those who completed the study was $54.1 \pm 8.1$ years. Table 2 shows the baseline characteristics of the study participants.

\section{Compliance with the DASH-JUMP dietary intervention}

We analyzed participants' intake of each supplied meal using a life checklist which participants completed daily. The results showed that the mean compliance with consuming the supplied meals was $92.2 \%$ for the first round (of 2 weeks), $89.8 \%$ for the second round, $86.9 \%$ for the third round and $84.9 \%$ for the fourth round. Participants' records showed a mean compliance of $88.5 \%$ for the full 2 months of the intervention period. The mean salt intake of participants, as calculated from the meal intakes they recorded in the life checklist during the intervention period, was $6.9 \mathrm{~g}$ per day.

\section{BP after the DASH-JUMP dietary intervention}

Figure 2 shows the SBP and DBP of participants obtained by selfmonitoring using an automatic BP monitor in their homes every day for 6 months. After participants started on the DASH-JUMP diet, there was a clear fall in the mean SBP and DBP of the participants starting from 3 to 7 days after beginning the diet. Furthermore, the DASH-JUMP diet resulted in a rapid decrease of SBP and DBP toward the normal range, but once a normal BP was achieved, it became stabilized and continuation of the DASH-JUMP diet did not further decrease BP to the hypotensive range, which can be achieved with antihypertensive drug therapy.

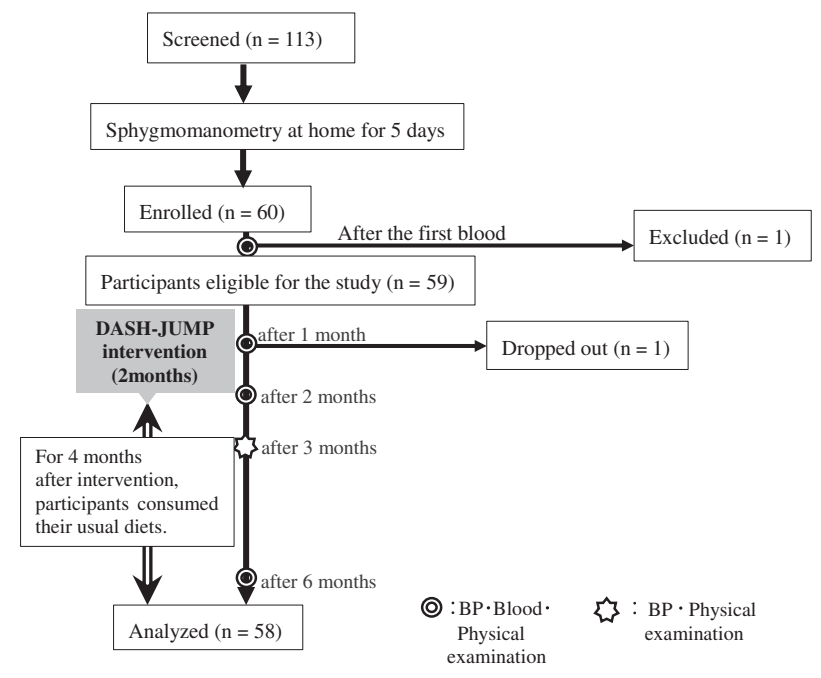

Figure 1 Flow diagram of the phases of the DASH-JUMP study.
Index 1 of Table 3 shows the SBP and DBP measurements made at baseline in our laboratory when participants visited for medical examinations and the follow-up visits after 1, 2, 3 and 6 months. The laboratory measurements confirmed that both SBP and DBP significantly decreased after participants started the DASH-JUMP diet, and both measurements increased towards hypertensive values after the completion of the dietary intervention period. The significant differences of post hoc analysis from baseline to each point are shown as $P$-values in Table 3 (footnote $b$ ).

\section{Indices of lifestyle-related diseases and serum lipids}

The mean indices of lifestyle-related diseases (body weight, BMI, abdominal circumference, hip circumference, AST, ALT and $\gamma$-GTP) at each tested time-point (baseline and 1, 2, 3 and 6 months of the DASH-JUMP intervention) are compared in Index 1 of Table 3. DASH-JUMP resulted in significant reductions in participants' mean weight, BMI, hip circumference, AST, ALT and $\gamma$-GPT values. The abdominal circumference values decreased gradually and were significantly decreased 1 month after the discontinuation of the diet. DASH-JUMP also resulted in significant reductions in the mean serum levels of total cholesterol, LDL-C, HDL-C, triglycerides, apoA-1, apoB and apoE. ApoB/apoA-1 ratio were significantly decreased at 4 months after ceasing intervention $(P=0.024$ compared with after 2 months). These data are summarized in Index 2 of Table 3.

\section{Insulin sensitivity}

DASH-JUMP resulted in significant reductions in the levels from baseline of fasting serum glucose after 2 months, HbAlC after 1 month, fasting insulin after 2 months, HOMA-IR and HOMA- $\beta$ after 2 months. These data are summarized in Index 3 of Table 3.

\section{Inflammatory cytokines and other measurements}

Significant reductions from baseline were found in the serum levels of IL-6, NT-proBNP, adiponectin and urinary microalbumin during the DASH-JUMP intervention period. Significant increase from baseline was detected in the serum levels of renin. No significant changes were found in the serum levels of hs-CRP and uric acid, compared with that measured at baseline. The serum level of NT-proBNP and homocysteine significant increased at 4 months after ceasing intervention, compared with that measured at baseline. These data are summarized in Index 4 of Table 3.

\section{Electrolyte concentrations in serum and urine}

Serum concentrations of sodium significantly increased at 4 months after ceasing intervention, compared with that measured at baseline. And, the urinary concentrations of sodium significantly decreased during the DASH-JUMP intervention period and significantly increased at 4 months after ceasing intervention $(P=0.000$ compared with after 1 month or 2 months). The potassium and the urinary concentrations of potassium significantly increased during the intervention period. These data are summarized in Index 5 of Table 3 .

\section{Multiple regression analysis}

We used the changes in SBP or DBP from baseline to 1 month or 2 months as a dependent variable and the changes of cardiometabolic and inflammatory biomarkers from baseline to 1 month or 2 months of the DASH-JUMP diet as independent variables. We performed a multiple linear regression and excluded variables with a correlation coefficient of 0.4 or more. We then used variables with a variance inflation factor of $<2$, as independent variables. We found that the change in the concentration of urinary potassium from baseline to 
Table 2 Baseline characteristics of analyzed participants

\begin{tabular}{lc}
\hline Characteristic & \\
\hline$n$ & \\
Sex (male/female) & 58 \\
Age (years) & $30 / 28$ \\
Weight (kg) & $54.1 \pm 8.1$ \\
Sleep (h) & $66.4 \pm 12.1$ \\
Family history (\%) & $6.5 \pm 0.7$ \\
Current smokers (\%) & 54 \\
Past smokers (\%) & 15 \\
Alcohol drinking (\%) & 33 \\
Taking snacks (\%) & 56 \\
Physical activity (\%) & 80 \\
$\quad$ Light & \\
Moderate & \\
High & 24 \\
\hline
\end{tabular}

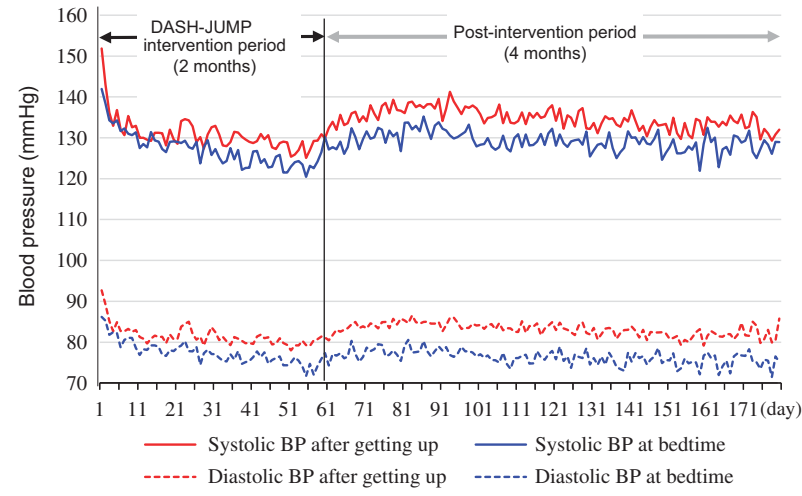

Figure $2 \mathrm{BP}$ measured by subjects at home during and after the DASHJUMP intervention period. Participants monitored BP with an automatic monitor in their home every day for 6 months.

1 month of the DASH-JUMP diet was a significant independent predictor of the changes in SBP from baseline to 1 month (Index 1 of Table 4). Similarly, the changes in total cholesterol from baseline to 1 month was a significant independent predictor of the change in DBP from baseline to 1 month (Index 2 of Table 4). And, the changes in BMI and urinary microalbumin were significant independent predictors of the change in SBP from baseline to 2 months (Index 3 of Table 4). We then found that the changes in BMI and apoE were significant independent predictors of the change in DBP from baseline to 2 months (Index 4 of Table 4).

\section{DISCUSSION}

In the present study, we have shown that the DASH-JUMP diet significantly reduces BP and cardiometabolic risk factors in Japanese participants with high-normal BP and stage 1 hypertension. Our collaborative project team designed a 14-day menu comprising 42 different meals of Japanese food that met the nutrient criteria of the DASH diet used in Western countries; something that had not previously been achieved.

The DASH-JUMP diet was provided to participants continuously for 2 months. Participants described their intake of each food in a life checklist every day, and they showed a mean compliance of $88.5 \%$. This high level of compliance indicates that the DASH-JUMP diet generally meets the dietary preferences of Japanese people, and induces a marked hypotensive effect. The hypotensive effect was relatively rapid, with a marked decrease in $\mathrm{BP}$ observed between the third and seventh days of the intervention period (Figure 2). From baseline to 2 months later, the mean SBP measured by medical examination in our laboratory had decreased by $23.5 \mathrm{~mm} \mathrm{Hg}$, and the mean DBP had decreased by $11.8 \mathrm{~mm} \mathrm{Hg}$. Sodium restriction ${ }^{18,26,27}$ was considered to be a factor underlying the hypotensive effect observed in this study. The mean salt intake of people consuming a normal Japanese diet was $10.2 \mathrm{~g}$ per day (male $11.1 \mathrm{~g}$ per day, female $9.4 \mathrm{~g}$ per day), but with the DASH-JUMP diet, the mean salt intake of participants was reduced by $\sim 3$ g per day. The hypotensive effect shown in this study was similar to that shown in a previous study that achieved approximately the same amount of reduction in sodium intake. ${ }^{17}$

An increase in the mean concentration of urinary potassium during the DASH-JUMP intervention period influenced SBP from baseline to 1 month, as shown by the results of a multiple regression analysis conducted to determine the factors that most closely correlated with the changes in SBP from baseline to 1 month. The mean serum potassium concentration was only slightly increased during the DASHJUMP intervention period, but, at 1 and 2 months of the intervention period, the mean potassium concentration in urine was almost double that measured at baseline. These results and those of previous studies $^{28,29}$ suggest that the high level of potassium in the DASH and DASH-JUMP diets is important for its hypotensive effects. Based on previous studies on the original DASH diet, the World Health Organization recommends that dietary potassium intake should be increased to decrease the risks of high BP and cardiovascular diseases, including stroke and ischemic heart disease. The World Health Organization guidelines recommend a daily intake of $3510 \mathrm{mg}$ of potassium for adults. ${ }^{30}$ It was considered that the high potassium content of the DASH-JUMP diet could result in hyperkalemia and safety monitoring was conducted. During the study period, a temporary decrease in the estimated glomerular filtration rate (e-GFR) occurred in four participants, reaching the range of chronic kidney disease stage G3A (mild-to-moderate stage). These decreases in e-GFR returned to baseline 4 months after the end of the intervention period. Additionally, four participants had hyperkalemia throughout the intervention period; however, these participants showed no abnormalities in e-GFR, and their potassium levels were normalized after the intervention period. No serious adverse events occurred during this study, and the safety of the participants was monitored and confirmed throughout the study period.

Multiple linear regression analysis showed that the change of the SBP for DASH-JUMP intervention from baseline to 2 months is mostly influenced by the change in BMI and urinary microalbumin levels from baseline to 2 months. Participants' mean body weight decreased by $\sim 4 \mathrm{~kg}$ during the intervention with the DASH-JUMP diet, which has a low fat content and provides $1650-1820 \mathrm{kcal}$ per day. According to the results of a previous study, ${ }^{31}$ higher dietary fiber intake was associated with lower BMI and waist-to-hip ratio. The degree of weight loss was similar to those reported by a previous study investigating the unmodified DASH diet. ${ }^{17}$ Furthermore, the value of urinary microalbumin, a risk factor of heart failure and renal dysfunction and a marker of the systemic dysfunction of vascular endothelial cells, decreased but stayed within the normal range. Participants' mean DBP also decreased during the intervention period, and this change correlated with the serum levels of total cholesterol, apoE and BMI. It should be noted that the BMI that could measure easily was the most important indexes of lifestyle-related diseases from results of this study. 
Table 3 Effects of the DASH-JUMP diet on indices of lifestyle-related diseases, serum lipids, insulin sensitivity, inflammatory cytokines and other measurements

\begin{tabular}{|c|c|c|c|c|c|c|c|}
\hline Indices & $\mathrm{n}$ & Baseline & After 1 month & After 2 months & $\begin{array}{l}1 \text { month after } \\
\text { ceasing intervention }\end{array}$ & $\begin{array}{l}4 \text { months after } \\
\text { ceasing intervention }\end{array}$ & P-value \\
\hline \multicolumn{8}{|l|}{1} \\
\hline Diastolic blood pressure $(\mathrm{mm} \mathrm{Hg})$ & 58 & $91 \pm 11$ & $81 \pm 9 * *$ & $80 \pm 9 * *$ & $84 \pm 11^{* *}$ & $85 \pm 10 * *$ & 0.000 \\
\hline Weight (kg) & 58 & $66.4 \pm 12.1$ & $64.1 \pm 11.5^{* *}$ & $62.5 \pm 11.3^{* *}$ & $62.9 \pm 11.5^{* *}$ & $63.7 \pm 11.8^{* *}$ & 0.000 \\
\hline Body mass index $\left(\mathrm{kg} \mathrm{m}^{-2}\right)$ & 58 & $24.6 \pm 3.5$ & $23.8 \pm 3.4^{* *}$ & $23.2 \pm 3.3^{* *}$ & $23.3 \pm 3.3^{* *}$ & $23.6 \pm 3.4^{* *}$ & 0.000 \\
\hline AST $\left(\left.I U\right|^{-1}\right)$ & 58 & $26 \pm 9$ & $24 \pm 11$ & $22 \pm 7^{* *}$ & & $23 \pm 8^{* *}$ & 0.000 \\
\hline $\operatorname{ALT}\left(\left.I \cup\right|^{-1}\right)$ & 58 & $28 \pm 14$ & $25 \pm 14$ & $21 \pm 10^{* *}$ & & $22 \pm 14^{* *}$ & 0.000 \\
\hline$\gamma$-GTP $\left(I \cup I^{-1}\right)$ & 58 & $51 \pm 48$ & $38 \pm 37^{* *}$ & $31 \pm 26^{* *}$ & & $50 \pm 69$ & 0.000 \\
\hline \multicolumn{8}{|l|}{2} \\
\hline Total cholesterol (mg dl-1) & 58 & $216 \pm 33$ & $184 \pm 32^{* *}$ & $182 \pm 34^{* *}$ & & $199 \pm 34^{* *}$ & 0.000 \\
\hline ApoB $\left(\mathrm{mg} \mathrm{dl}^{-1}\right)$ & 58 & $106 \pm 21$ & $90 \pm 20^{* *}$ & $88 \pm 20^{* *}$ & & $94 \pm 20^{* *}$ & 0.000 \\
\hline ApoB/apoA-1 & 58 & $0.72 \pm 0.19$ & $0.74 \pm 0.22$ & $0.74 \pm 0.22$ & & $0.68 \pm 0.20$ & 0.019 \\
\hline ApoE (mg dl $\left.{ }^{-1}\right)$ & 58 & $4.5 \pm 1.5$ & $3.8 \pm 1.2^{* *}$ & $3.9 \pm 1.3^{* *}$ & & $4.3 \pm 1.7$ & 0.000 \\
\hline \multicolumn{8}{|l|}{3} \\
\hline Fasting serum glucose $\left(\mathrm{mg} \mathrm{dl}^{-1}\right)$ & 58 & $100 \pm 26$ & $97 \pm 17$ & $94 \pm 15^{* *}$ & & $94 \pm 13^{* *}$ & 0.001 \\
\hline $\mathrm{HbA} 1 \mathrm{C}(\%)$ & 58 & $5.58 \pm 0.84$ & $5.45 \pm 0.73^{* *}$ & $5.62 \pm 0.57$ & & $5.59 \pm 0.45$ & 0.000 \\
\hline Fasting insulin $\left(\mu \mid \cup \mathrm{ml}^{-1}\right)$ & 58 & $6.9 \pm 5.9$ & $7.5 \pm 9.1$ & $4.4 \pm 2.7^{* *}$ & & $5.4 \pm 3.3$ & 0.000 \\
\hline HOMA-IR & 58 & $1.8 \pm 2.3$ & $1.9 \pm 2.4$ & $1.1 \pm 0.8^{* *}$ & & $1.3 \pm 0.8$ & 0.000 \\
\hline НОМА- $\beta$ & 58 & $71 \pm 39$ & $83 \pm 79$ & $54 \pm 31^{* *}$ & & $67 \pm 36$ & 0.000 \\
\hline Uric acid $\left(\mathrm{mg} \mathrm{dl}^{-1}\right)$ & 58 & $5.6 \pm 1.4$ & $5.6 \pm 1.4$ & $5.6 \pm 1.4$ & & $5.5 \pm 1.2$ & 0.381 \\
\hline \multicolumn{8}{|l|}{5} \\
\hline Serum potassium (mEq $\mathrm{I}^{-1}$ ) & 58 & $4.3 \pm 0.4$ & $4.6 \pm 0.4^{* *}$ & $4.6 \pm 0.4^{* *}$ & & $3.9 \pm 0.3^{* *}$ & 0.000 \\
\hline Serum sodium $\left(m E q I^{-1}\right)$ & 58 & $140 \pm 2$ & $141 \pm 2$ & $140 \pm 1$ & & $142 \pm 2^{* *}$ & 0.000 \\
\hline Urinary potassium (mEq $\left.\right|^{-1}$ ) & 58 & $45 \pm 23$ & $81 \pm 37^{* *}$ & $85 \pm 35^{* *}$ & & $60 \pm 29 * *$ & 0.000 \\
\hline Urinary sodium (mEq ${ }^{-1}$ ) & 58 & $135 \pm 7$ & $82 \pm 5^{* *}$ & $87 \pm 5^{* *}$ & & $146 \pm 8$ & 0.000 \\
\hline
\end{tabular}

Abbreviations: ALT, alanine aminotransferase; ANOVA, analysis of variance; Apo, apolipoprotein; AST, aspartate aminotransferase; DASH, Dietary Approaches to Stop Hypertension; DASH-JUMP, DASH-Japan Ube Modified diet Program; $\gamma$-GTP, $\gamma$-glutamyl transpeptidase; HbA1C, hemoglobin A1C; HDL-C, high-density lipoprotein-cholesterol; HOMA, homeostatic model assessments of insulin resistance and pancreatic beta cell function; HOMA-IR, homeostatic model assessments of insulin resistance; hs-CRP, high sensitivity C-reactive protein; IL-6, interleukin-6; LDL-C, low-density lipoprotein-cholesterol; NT-proBNP, N-terminal prohormone of brain natriuretic peptide.

1: Indices of lifestyle-related diseases; 2: serum lipids; 3: insulin sensitivity; 4: inflammatory cytokines and others; 5: electrolyte concentrations in serum and urine.

Data are means + s.d. a $P$-values derived from repeated-measures ANOVA or Friedman's test. 'b $P$-values derived from post hoc analysis with Bonferroni or Friedman's test for multiple comparisons.

${ }^{* *}$ indicates ${ }^{\mathrm{b}} P<0.01$ vs. baseline; ${ }^{*}$ indicates ${ }^{\mathrm{b}} P<0.05$ vs. baseline. A value of $P<0.05$ was considered significant. We excluded three outliers of triglyceride, and analyzed 55 cases.

The study results indicated that the DASH-JUMP diet reduced several biomarkers and risk factors related to the development of lifestyle-related diseases including participants' mean body weight, BMI, abdominal circumference, hip circumference, AST, ALT and $\gamma$-GTP. All of these changes indicate improvements in overall health and can be expected to lower the risk for developing cardiovascular disease, among other diseases. ${ }^{32}$ Other beneficial changes found during the DASH-JUMP intervention period were significantly decreased serum concentrations of total cholesterol, LDL-C, triglycerides, apoB and apoE. These changes presumably resulted from the low saturated fatty acid and cholesterol contents ${ }^{19,33-35}$ of the DASH-JUMP diet and show that DASH-JUMP could be used to assist in the treatment of patients with lipid metabolism disorders, such as hyperlipidemia. Previous studies ${ }^{36-38}$ have shown that the original DASH diet improved the health of participants with type 2 diabetes mellitus. In this study, we measured parameters related to glucose metabolism; 
Table 4 Multiple regression analysis for determinants of the change in blood pressure

\begin{tabular}{|c|c|c|c|c|c|c|}
\hline & \multirow[b]{2}{*}{ Dependent variable } & \multirow[b]{2}{*}{ Independent variable } & \multicolumn{2}{|c|}{ Unadjusted } & \multirow[b]{2}{*}{$\beta$} & \multirow[b]{2}{*}{ P-value } \\
\hline & & & $r$ & P-value & & \\
\hline \multirow[t]{5}{*}{1} & The change in SBP from baseline to 1 month & $\left(R^{2}=0.181\right)$ & & & & \\
\hline & & Urinary potassium & -0.335 & 0.008 & -0.316 & 0.024 \\
\hline & & Urinary microalbumin & 0.219 & 0.059 & 0.165 & 0.227 \\
\hline & & ApoE & 0.165 & 0.121 & 0.197 & 0.144 \\
\hline & & Serum sodium & 0.066 & 0.320 & 0.090 & 0.502 \\
\hline 2 & The change in DBP from baseline to 1 month & $\left(R^{2}=0.243\right)$ & & & & \\
\hline & & Total cholesterol & 0.395 & 0.002 & 0.480 & 0.001 \\
\hline & & NT-proBNP & 0.027 & 0.426 & 0.194 & 0.168 \\
\hline & & ApoE & 0.224 & 0.057 & 0.219 & 0.098 \\
\hline & & Uric acid & 0.008 & 0.479 & -0.094 & 0.481 \\
\hline \multirow[t]{9}{*}{3} & The change in SBP from baseline to 2 months & $\left(R^{2}=0.470\right)$ & & & & \\
\hline & & BMI & 0.539 & 0.000 & 0.598 & 0.000 \\
\hline & & Urinary microalbumin & 0.276 & 0.025 & 0.424 & 0.002 \\
\hline & & ApoA-1 & 0.294 & 0.018 & 0.036 & 0.783 \\
\hline & & Fasting serum glucose & 0.102 & 0.238 & 0.080 & 0.520 \\
\hline & & Urinary potassium & -0.120 & 0.200 & 0.077 & 0.551 \\
\hline & & Serum potassium & -0.059 & 0.341 & -0.038 & 0.765 \\
\hline & & Serum sodium & 0.028 & 0.423 & -0.023 & 0.852 \\
\hline & & NT-proBNP & -0.197 & 0.082 & -0.102 & 0.431 \\
\hline \multirow[t]{8}{*}{4} & The change in DBP from baseline to 2 months & $\left(R^{2}=0.345\right)$ & & & & \\
\hline & & $\mathrm{BMI}$ & 0.392 & 0.002 & 0.403 & 0.003 \\
\hline & & ApoE & 0.343 & 0.006 & 0.270 & 0.047 \\
\hline & & Uric acid & 0.213 & 0.064 & 0.078 & 0.556 \\
\hline & & Serum potassium & 0.135 & 0.170 & 0.211 & 0.128 \\
\hline & & Serum sodium & 0.010 & 0.471 & -0.019 & 0.882 \\
\hline & & Fasting serum glucose & 0.031 & 0.412 & 0.099 & 0.458 \\
\hline & & Urinary microalbumin & 0.220 & 0.590 & 0.209 & 0.117 \\
\hline
\end{tabular}

Abbreviations: Apo, apolipoprotein; BMI, body mass index; DBP, diastolic BP; NT-proBNP, N-terminal prohormone of brain natriuretic peptide; SBP, systolic BP.

1: The change in independent variables from baseline to 1 month.

2: The change in independent variables from baseline to 1 month.

3: The change in independent variables from baseline to 2 months.

4: The change in independent variables from baseline to 2 months.

interestingly, we found that the fasting serum concentrations of glucose and insulin, as well as the HOMA- $\beta$ score, a measures of pancreatic $\beta$-cell function used to assess insulin resistance, was significantly decreased during the DASH-JUMP intervention period. Furthermore, the results indicate carbohydrate metabolism improvement in this hypertensive population. We did not find a significant effect of the DASH-JUMP on hs-CRP levels; however, the serum concentrations of IL-6 and NT-proBNP significantly decreased, suggestive of an improvement in inflammatory biomarker. ${ }^{39}$ DASH-JUMP showed a great hypotensive effect and improved indices of lifestyle-related diseases as well as lipid profile. In addition, DASH-JUMP may improve carbohydrate metabolism.

At 4 months after ceasing intervention, NT-proBNP, which is a diagnostic marker for heart failure, rose to $52 \pm 36 \mathrm{mg} \mathrm{dl}^{-1}$ (heart failure sign $\geqslant 55$ ), and it is elevation within normal limit. Since the sodium intake of participants increased after the DASH-JUMP intervention period, and their potassium intake decreased, their sodium-potassium ratio would have risen. According to a previous study by Yang et al., ${ }^{40}$ a higher sodium-potassium ratio is associated with a significantly increased risk of cardiovascular disease. There is a possibility that, in such a situation, potassium-sodium interaction could exacerbate the value of NT-proBNP. This result suggests that for future studies on DASH-JUMP, it is necessary to follow up for 6 months after ceasing the intervention. On the other hand, apoB/apoA-1 ratio that is associated with future CAD events independent of standard cardiovascular risk factors (diabetes, body mass index, smoking, systolic BP and C-reactive protein level) and lipid values (LDL-C, HDL-C and triglyceride levels, and, in a separate model, total cholesterol-HDL-C ratio), is considered to be a strong risk factor for atherosclerotic cardiovascular disease. ${ }^{41}$ ApoB/apoA-1 ratio were significantly decreased at 4 months after ceasing intervention. It can be presumed that the risk of developing atherosclerotic cardiovascular disease has decreased at 4 months after ceasing intervention.

In the case of studies involving the distribution of a prepared diet to participants, such as this study, it is a concern that it may be difficult for participants to continue the diet after the end of the intervention period. Study participants consumed the DASH-JUMP diet for 2 months, which may have helped them to recognize similar healthpromoting foods through sight and taste following the intervention period. Interestingly, both SBP and DBP rose after the intervention ended, but their BP hardly changed between 1 and 4 months after ceasing the intervention. This indicates that participants may have reflected on their $\mathrm{BP}$ having risen at 1 month after ceasing the 
intervention and consequently began to follow dietary habits more closely resembling DASH-JUMP after 1 month.

However, at 4 months after ceasing intervention, participants' mean excretion of urinary sodium rebounded highly, and the mean excretion of urinary potassium was moderately higher than it was at baseline. These observations indicated that the eating habits of the DASH diet were not continued long term. From these results, we concluded that it is necessary to examine the reinforcement of the knowledge gained by the participants via their experience of DASH-JUMP with a continuous nutrition education program in future. Also, it is necessary to examine the inclusion of a self-monitoring device for the measurement of urinary salt ${ }^{42}$ when we conduct a nutrition education program. Enabling participants to monitor changes in their urinary sodium and potassium excretion and compare the results with the contents of their dietary intake may enhance the efficacy of nutrition education.

From these, it should be noted that the hypotensive effect of DASHJUMP is obtained as well as sodium restriction by the synergy such as minerals, dietary fiber and low fat.

DASH-JUMP has the disadvantage that the serum levels of HDL-C and apoA-1, which are involved in the process of reverse cholesterol transport, were reduced in the DASH-JUMP group. Because HDL-C and apoA-1 have important functions as defense mechanisms against arteriosclerosis, it is necessary to improve DASH-JUMP more to increase the serum levels of HDL-C. It is suggested that we should examine the diet and particularly the inclusion of safflower oil, nuts, soy bean foods and fish oil to raise the serum levels of HDL-C for a future version of DASH-JUMP.

In conclusion, the results indicated that this diet may be an effective nutritional strategy to prevent cardiovascular events in Japanese people with high BP.

\section{Study limitations}

This study had some limitations that require consideration. First, relatively few participants were included in the study, and therefore the statistical power of this study was low. Second, this study was an open-label, single-arm trial. There is the bias that, because participants know they are being provided with the experimental diet, their compliance may rise compared with that of participants in the study that established the control group. This was a pilot study, and we intend to conduct a randomized controlled trial in the future to better evaluate the potential benefits of the DASH-JUMP diet for Japanese people with high-normal BP and stage 1 hypertension.

\section{CONFLICT OF INTEREST}

Dr. Umemoto is supported by a research grant from Yamaguchi Prefecture, Japan, and Kyowa Hakko Kirin, Co., Ltd., and also received consultant fee from Maruha Nichiro Holdings, Inc. The other authors declare no conflict of interest.

\section{ACKNOWLEDGEMENTS}

We received financial support for the study from a grant of the Maruha Nichiro. We extend a heartfelt thank you to all the study participants for the faith they placed in our study. We also thank the people who extended their cooperation for this study. This work was supported in part by JSPS KAKENHI Grant No. 15K0923.

1 Tamiya N, Noguchi H, Nishi A, Reich MR, Ikegami N, Hashimoto H, Shibuya K, Kawachi I, Campbell JC. Population ageing and wellbeing: lessons from Japan's longterm care insurance policy. Lancet 2011; 378: 1183-1192.
2 Japanese Health, Labor and Welfare Statistics Association. Health and welfare statistics (in Japanese). J Health Welfare Stat 2013; 60: 88-103.

3 Ueshima H. Evidence of Circulatory Disease Based on NIPPON DATA (in Japanese). Japan Medical Journal: Tokyo, Japan, 2008, pp 3-41.

4 Chobanian AV, Bakris GL, Black HR, Cushman WC, Green LA, Izzo JL Jr, Jones DW, Materson BJ, Oparil S, Wright JT Jr, Roccella EJ, Lenfant C, Carter BL, Cohen JD, Colman PJ, Cziraky MJ, Davis JJ, Ferdinand KC, Gifford RW Jr, Glick M, Havas S, Hostetter TH, Kirby L, Kolasa KM, Linas S, Manger WM, Marshall EC, Merchant J, Miller NH, Moser M, Nickey WA, Randall OS, Reed JW, Shaughnessy L, Sheps SG, Snyder DB, Sowers JR, Steiner LM, Stout R, Strickland RD, Vallbona C, Weiss HS, Whisnant JP, Wilson GJ, Winston M. The seventh report of the Joint National Committee on prevention, detection, evaluation, and treatment of high blood pressure (JNC 7). JAMA 2003; 289: 2560-2571.

5 Lawes CM, Hoorn SV, Rodgers A. Global burden of blood-pressure-related disease, 2001. Lancet 2008; 371: 1513-1518.

6 Shimamoto K, Ando K, Fujita T, Hasebe N, Higaki J, Horiuchi M, Imai Y, Imaizumi T, Ishimitsu $\mathrm{T}$, Ito $\mathrm{M}$, Ito $\mathrm{S}$, Itoh $\mathrm{H}$, Iwao $\mathrm{H}$, Kai H, Kario $\mathrm{K}$, Kashihara $\mathrm{N}$, Kawano $\mathrm{Y}$, Kim-Mitsuyama S, Kimura G, Kohara K, Komuro I, Kumagai H, Matsuura H, Miura K, Morishita R, Naruse M, Node K, Ohya Y, Rakugi H, Saito I, Saitoh S, Shimada K, Shimosawa T, Suzuki H, Tamura K, Tanahashi N, Tsuchihashi T, Uchiyama M, Ueda S, Umemura S, on behalf of The Japanese Society of Hypertension Committee The Japanese Society of Hypertension Guidelines for the Management of Hypertension (JSH 2014). Hypertens Res 2014 37: 260-392.

7 Lichtenstein AH, Appel LJ, Brands M, Carnethon M, Daniels S, Franch HA, Franklin B, Kris-Etherton P, Harris WS, Howard B, Karanja N, Lefevre M, Rudel L, Sacks F, Horn LV, Winston M, Wylie-Rosett J. Diet and lifestyle recommendations revision 2006: a scientific statement from the American Heart Association Nutrition Committee. Circulation 2006; 114: 82-96.

8 Kaplan N, Mendis S, Poulter N, Whitworth J. 2003 World Health Organization (WHO)/ International Society of Hypertension (ISH) statement on management of hypertension. J. Hypertens 2003; 21: 1983-1992.

9 Mancia G, Fagard R, Narkiewicz K, Redón J, Zanchetti A, Böhm M, Christiaens T, Cifkova R, Backer GD, Dominiczak A, Galderisi M, Grobbee DE, Jaarsma T, Kirchhof $P$, Kjeldsen SE, Laurent S, Manolis AJ, Nilsson PM, Ruilope LM, Schmieder RE, Sirnes PA, Sleight P, Viigimaa M, Waeber B, Zannad F, Burnier M, Ambrosioni E, Caufield M, Coca A, Olsen MH, Schmieder RE, Tsioufis C, Van de Borne $P$, Zamorano JL, Achenbach S, Baumgartner H, Bax JJ, Bueno H, Dean V, Deaton C, Erol C, Ferrari R, Hasdai D, Hoes AW, Knuuti J, Kolh P, Lancellotti P, Linhart A, Nihoyannopoulos P, Piepoli M, Tamargo JL, Tendera M, Torbicki A, Wijns W, Windecker S, Clement D, Gillebert T, Rosei EA, Anker SD, Bauersachs J, Hitij JB, BUYZERE MD, Geest SD, Derumeaux GA, Erdine S, Farsang C, Funck-Brentano C, Gerc V, Germano G, Gielen S, Haller H, Jordan J, Kahan T, Komajda M, Lovic D, Mahrholdt H, Ostergren J, Parati G, Perk J, Polonia J, Popescu BA, Reiner Ž, Rydén L, Sirenko Y, Stanton A, Struijker-Boudier H, Vlachopoulos C, Volpe M, Wood DA. The 2013 ESH/ESC guidelines for the management of arterial hypertension. Eur Heart J 2013 34: 2159-2219.

10 Brown IJ, Tzoulaki I, Candeias V, Elliott P. Salt intakes around the world: implications for public health. Int J Epidemiol 2009; 38: 791-813.

11 Kawano Y, Tsuchihashi T, Matsuura H, Ando K, Fujita T, Ueshima H. Report of the Working Group for Dietary Salt Reduction of the Japanese Society of Hypertension: (2) assessment of salt intake in the management of hypertension. Hypertens Res 2007; 30: 887-893.

12 Sasaki N. High blood pressure and the salt intake of the Japanese. Jpn Heart J 1962; 3: 313-324.

13 National Institute of Health and Nutrition, Japan. Overview of Dietary Reference Intakes for Japanese (2015). Ministry of Health, Labour and Welfare: Japan, 2015, pp 1-42.

14 Toda A, Ishizaka Y, Tani M, Yamakado M. Current dietary salt intake of Japanese individuals assessed during health check-up. Hypertens Res 2015; 38: 163-168.

15 Okuda N, Nishi N, Ishikawa-Takata K, Yoshimura E, Horie S, Nakanishi T, Sato Y, Takimoto $\mathrm{H}$. Understanding of sodium content labeled on food packages by Japanese people. Hypertens Res 2014; 37: 467-471.

16 Sacks FM, Svetkey LP, Vollmer WM, Appel LJ, Bray GA, Harsha D, Obarzanek E, Conlin PR, Miller ER III, Simons-Morton DG, Karanja N, Lin PH, Alexander N, Belmonte J, Bodden F, Cashman L, Cox B, Dyer J, Ghosh A, Hackett J, Hamilton E, Holiday T, Karimbakis J, Larson C, McCullough M, McDonald D, McVinney P, Moeller D, Morris P, Myrie M, Osborn K, Penachio E, Redican S, Sales J, Swain J, Than Z, Weed K, Abbott J, Aicher K, Ard J, Baughman J, Baughman M, Brown B, Bohannon A, Graves B, Hoben K, Huang J, Johnson-Pruden L, Phelps T, Plaisted C, Reams L, Reams $P$, Ross T, Rukenbrod F, Ward E, Abshere J, Bengough D, Bohlman L, Charleston J, Clement L, Dahne C, Dennis F, Dobry S, Eldridge K, Erlinger T, Fouts A, Harris C, Horseman B, Jehn M, Kritt S, Lambert J, Levitas E, McCarron P, Muhammad N, Nagy M, Peterson B, Rhodes D, Shank V, Shields T, Stanger T, Thomas A, Thomas E, Thomas L, Weiss R, Wilke E, Wong W, Allison M, Baxter S, Becker N, Craddick S, Doster B, Eddy C, Ernst D, Garrison A, Gillespie S, Gould R, Haswell T, Haworth L, Heinith F, Hornbrook M, Kirk K, LaChance PA, Laws R, Leitch M, Li WR, Massinger L, McMurray M, Meltesen G, Miranda G, Mitchell S, Redmond N, Reinhardt J, Rice J, Runk $P$, Schuler R, Souvanlasy $C$, Sucec M, Vogt T, Champagne C, Crawford S, Greenway F, Ihrig J, Kennedy B, Perault J, Sanford D, Sawyer A, Smith S, Tulley R, Vaidyanathan J. Effects on blood pressure of reduced dietary sodium and the Dietary Approaches to Stop Hypertension (DASH) diet. N Engl J Med 2001; 344: 3-10.

17 He FJ, MacGregor GA. How far should salt intake be reduced? Hypertension 2003; 42: 1093-1099.

18 Appel LJ, Frohlich ED, Hall JE, Pearson TA, Sacco RL, Seals DR, Sacks FM, Smith SC Jr, Vafiadis DK, Van Horn LV. The importance of population-wide sodium reduction as a 
means to prevent cardiovascular disease and stroke: a call to action from the American Heart Association. Circulation 2011; 123: 1138-1143.

19 Appel LJ, Champagne CM, Harsha DW, Cooper LS, Obarzanek E, Elmer PJ, Stevens VJ, Vollmer WM, Lin PH, Svetkey LP, Young DR. Effects of comprehensive lifestyle modification on blood pressure control: main results of the PREMIER clinical trial. JAMA 2003; 289: 2083-2093.

20 Blumenthal JA, Babyak MA, Hinderliter A, Watkins LL, Craighead L, Lin PH, Caccia C, Johnson J, Waugh R, Sherwood A. Effects of the DASH Diet alone and in combination with exercise and weight Loss on blood pressure and cardiovascular biomarkers in men and women with high blood pressure: The ENCORE Study. Arch Intern Med 2010; 170 $126-135$.

21 United Nations Educational Scientific and Cultural Organization (UNESCO). Washoku, Traditional Dietary Cultures of the Japanese, Notably for the Celebration of New Year. Available at: http://www.unesco.org/culture/ich/en/RL/washoku-traditional-dietary-cultures-of-the-japanese-notably-for-the-celebration-of-new-year-00869 (last accessed 12 May 2015).

22 Moore T, Svetkey L, Lin PH, Karanja N, Jenkins M. The DASH Diet for Hypertension. The Free Press: New York, NY, USA, 2001, pp 125-203.

23 Appel LJ, Moore TJ, Obarzanek E, Vollmer WM, Svetkey LP, Sacks FM, Bray GA Vogt TM, Cutler JA, Windhauser MM, Lin PH, Karanja N, Proschan MA, LaChance P, Laws R, Eddy C, Rice J, Linton K, Haworth L, Adams N, Pearson K, Diller L, Taylor J, Conlin P, Jaffe L, McKnight J, MacDonald M, Nauth K, Courtney Y, Drezner M, Bales C, Carter L, Ard J, Plaisted C, Hoben K, Norris S, Reams P, Aicher K, Fike R, Ryan DH, Champagne CM, Wozniak PJ, McGee B, Crawford S, Kennedy BM, Caballero B, Kumanyika S, Jee S, Charleston J, McCarron P, Cappelli S, Harnish B, Coleman P, Stewart KK, Phillips K, McCarron D, Roullet JB, Illingworth R, Burns S, Lashley E, Spence JT. A clinical trial of the effects of dietary patterns on blood pressure. $N$ Engl J Med 1997; 336: 1117-1124.

24 Ministry of Health, Labor and Welfare. A Summary of Nationwide Health/Nutrition Survey Results (in Japanese). Ministry of Health, Labor and Welfare: Japan. Available at: http://www.mhlw.go.jp/file/04-Houdouhappyou-10904750-Kenkoukyoku-Gantaisakukenkouzoushinka/0000106403.pdf (last accessed 12 May 2015).

25 Imai Y, Kario K, Shimada K, Kawano Y, Hasebe N, Matsuura H, Tsuchihashi T, Ohkubo T, Kuwajima I, Miyakawa M. Japanese Society of Hypertension Committee for Guidelines for Self-monitoring of Blood Pressure at Home. The Japanese Society of Hypertension guidelines for self-monitoring of blood pressure at home (second edition). Hypertens Res 2012; 35: 777-795.

26 Pimenta E, Gaddam KK, Oparil S, Aban I, Husain S, Dell'Italia LJ, Calhoun DA. Effects of dietary sodium reduction on blood pressure in subjects with resistant hypertension results from a randomized trial. Hypertension 2009; 54: 475-481.

27 Cook NR, Obarzanek E, Cutler JA, Buring JE, Rexrode KM, Kumanyika SK, Appel LJ, Whelton PK, Trials of Hypertension Prevention collaborative Research Group. Joint effects of sodium and potassium intake on subsequent cardiovascular disease: the trials of hypertension prevention follow-up study. Arch Intern Med 2009; 169: 32-40.

28 Weaver CM. Potassium and health. Adv Nutr 2013; 4: 368S-377S.

29 Appel LJ, Brands MW, Daniels SR, Karanja N, Elmer PJ, Sacks FM. Dietary approaches to prevent and treat hypertension: a scientific statement from the American Heart Association. Hypertension 2006; 47: 296-308.

30 World Health Organization. Guideline: Potassium Intake for Adults and Children. WHO: Geneva, Switzerland, 2012, pp 1-38.

31 Lairon D, Arnault N, Bertrais S, Planells R, Clero E, Hercberg S, Boutron-Ruault MC. Dietary fiber intake and risk factors for cardiovascular disease in French adults. $\mathrm{Am} \mathrm{J}$ Clin Nutr 2005; 82: 1185-1194.
32 Whelton PK, He J, Appel LJ, Cutler JA, Havas S, Kotchen TA, Roccella EJ, Stout R, Vallbona C, Winston MC, Karimbakas J, National High Blood Pressure Education Program Coordinating Committee. Primary prevention of hypertension: clinical and public health advisory from the National High Blood Pressure Education Program. JAMA 2002; 288: 1882-1888

33 Obarzanek E, Sacks FM, Vollmer WM, Bray GA, Miller ER III, Lin PH, Karanja NM, Most-Windhauser MM, Moore TJ, Swain JF, Bales CW, Proschan MADASH Research Group. Effects on blood lipids of a blood pressure-lowering diet: the Dietary Approaches to Stop Hypertension (DASH) Trial. Am J Clin Nutr 2001; 74: 80-89.

34 Erlinger TP, Miller ER III, Charleston J, Appel LJ. Inflammation modifies the effects of a reduced-fat low-cholesterol diet on lipids: results from the DASH-sodium trial. Circulation 2003; 108: 150-154.

35 Hodson L, Harnden KE, Roberts R, Dennis AL, Frayn KN. Dose the DASH diet lower blood pressure by altering peripheral vascular function? J Hum Hypertens 2010; 24 312-319.

36 Liese AD, Bortsov A, Günther AL, Dabelea D, Reynolds K, Standiford DA, Liu L, Williams DE, Mayer-Davis EJ, D'Agostino RB Jr, Bell R, Marcovina S. Association of DASH diet with cardiovascular risk factors in youth with diabetes mellitus: the search for diabetes in youth study. Circulation 2011; 123: 1410-1417.

37 Hinderliter AL, Babyak MA, Sherwood A, Blumenthal JA. The DASH diet and insulin sensitivity. Curr Hypertens Rep 2011; 13: 67-73.

38 Ard JD, Grambow SC, Liu D, Slentz CA, Kraus WE, Svetkey LP. The effect of the PREMIER interventions on insulin sensitivity. Diabetes Care 2004; 27: 340-347.

39 Asemi Z, Samimi M, Tabassi Z, Sabihi SS, Esmaillzadeh A. A randomized controlled clinical trial investigating the effect of DASH diet on insulin resistance, inflammation, and oxidative stress in gestational diabetes. Nutrition 2013; 29: 619-624.

40 Yang Q, Liu T, Kuklina EV, Flanders WD, Hong Y, Gillespie C, Chang MH, Gwinn M, Dowling N, Khoury MJ, Hu FB. Sodium and potassium intake and mortality among US adults prospective data from the third national health and nutrition examination survey. Arch Intern Med 2011; 171: 1183-1191.

41 Steeg WA, Boekholdt SM, Stein EA, EL-Harchaoui K, Stroes ESG, Sandhu MS, Wareham NJ, Jukema JW, Luben R, Zwinderman AH, Kastelein JJP, Khaw K. Role of the apolipoprotein B-apolipoprotein $\mathrm{A}-\mathrm{I}$ ratio in cardiovascular risk assessment: a case-control analysis in EPIC-Norfolk. Ann Intern Med 2007; 146: 640-648.

42 Yasutake K, Horita N, Murata Y, Koyama S, Enjoji M, Tsuchihashi T. Estimated urinary salt excretion by a self-monitoring device is applicable to education of salt restriction. Hypertens Res 2015; 38: 143-148.

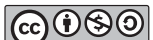

This work is licensed under a Creative Commons Attribution-NonCommercial-ShareAlike 4.0 International License. The images or other third party material in this article are included in the article's Creative Commons license, unless indicated otherwise in the credit line; if the material is not included under the Creative Commons license, users will need to obtain permission from the license holder to reproduce the material. To view a copy of this license, visit http://creativecommons.org/licenses/ by-nc-sa/4.0/

(C) The Author(s) 2016 